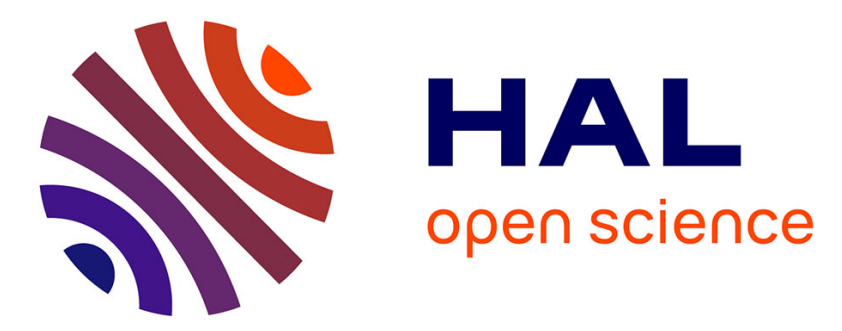

\title{
The deformometric kit: a method and an apparatus for monitoring the deformation of wooden panels
}

Luca Uzielli, Linda Cocchi, Paola Mazzanti, Marco Togni, Delphine Jullien, Paolo Dionisi-Vici

\section{- To cite this version:}

Luca Uzielli, Linda Cocchi, Paola Mazzanti, Marco Togni, Delphine Jullien, et al.. The deformometric kit: a method and an apparatus for monitoring the deformation of wooden panels. Journal of Cultural Heritage, 2012, pp.Voir DOI. 10.1016/j.culher.2012.03.001 . hal-00700825

\section{HAL Id: hal-00700825 \\ https://hal.science/hal-00700825}

Submitted on 24 May 2012

HAL is a multi-disciplinary open access archive for the deposit and dissemination of scientific research documents, whether they are published or not. The documents may come from teaching and research institutions in France or abroad, or from public or private research centers.
L'archive ouverte pluridisciplinaire HAL, est destinée au dépôt et à la diffusion de documents scientifiques de niveau recherche, publiés ou non, émanant des établissements d'enseignement et de recherche français ou étrangers, des laboratoires publics ou privés. 


\title{
The Deformometric Kit: a method and an apparatus for monitoring the deformation of wooden panels
}

\author{
Luca UZIELLI ${ }^{a}$, Linda COCCHI ${ }^{a}$, Paola MAZZANTI ${ }^{a}$, Marco TOGNI ${ }^{a}$, Delphine JULLIEN ${ }^{b}$, \\ Paolo DIONISI-VICI ${ }^{\mathrm{a}, \mathrm{c}}$ \\ ${ }^{a}$ DEISTAF, University of Florence (Italy) - 13 Via San Bonaventura - 50145 Firenze (Italy) \\ luca.uzielli@unifi.it, linda.cocchi@gmail.com , paola.mazzanti@unifi.it, marco.togni@unifi.it \\ ${ }^{5}$ Laboratoire de Mécanique et Génie Civil - UMR 5508, CNRS - Université Montpellier 2 - Place \\ E. Bataillon, cc 048 - 34095 Montpellier CDX 5 (France) Delphine.Jullien-Pierre@univ-montp2.fr \\ ${ }^{c}$ The Metropolitan Museum of Art, New York, NY (USA) paolo.dionisivici@metmuseum.org
}

\section{SUMMARY}

This paper describes the "Deformometric Kit" (DK), which is both a methodological approach and an equipment conceived, designed and made at DEISTAF (University of Florence). The DK's main purpose is to carry out measurements and monitoring of the deformation dynamics of wooden objects. The monitoring can take place in virtually any environment, for any desired duration (minutes, hours, weeks, years, and so on). The measurement can be carried out mainly, but not exclusively, in connection with fluctuations of ambient temperature and relative humidity. The DK provides a reliable and accurate record (a first step towards understanding) of the behaviour of original panel paintings placed in their usual exhibition location, enabling curatorial staff and researchers to (a) obtain information about the behaviour of individual supports, in order to evaluate the impact of climate on their conservation state, help to make decisions for future restoration interventions; and (b) provide reference data for calibrating and validating numeric models. It can also provide data on the deformation of a panel while it is handled and transported, enabling an evaluation of stresses to which it is subjected during this operation. The device consists of two displacement transducers, which are fixed (in a low-impact, reversible way) to the back face of the panel, perpendicular to the grain, at different distances from the panel's surface. The two transducers not only measure the in-plane shrinkage/swelling of the panel, but since they are located at different distances, their measurements can also be combined with simple geometrical calculations to indicate the amount of distortion (cupping) which the panel undergoes. This paper explains the geometrical principles on which the DK is based, as well as its construction. Some examples of the data which have been obtained during actual monitoring by the DK are also included.

KEYWORDS: Panel Paintings / Cupping of Wooden Supports / In-situ Monitoring / Environmentinduced distortion / Mechanics of Panel Paintings / Wood Technology / Transient Deformation / Data-loggers / Displacement Transducers /

\section{RESEARCH AIMS}

This paper describes a method used to monitor the deformation dynamics of panel paintings, based on the use of two transducers measuring the relative movement of two columns fixed on the back of the panel. It can be used in many contexts of conservation studies, like evaluating the effects of environmental variations or of handling and transportation, for supporting decisions about future restoration interventions, for providing reference data for calibrating and validating computer models.

\section{Introduction}




\section{Painted panels are basically wooden structures, of various sizes, that are often large and complex} such as large altarpieces. The panels are formed by a wooden support (one or more planks), to which a ground layer (gesso, glue, and sometimes canvas) has been applied, which in turn holds the paint layers and protective varnishes. Conserving panels means maintaining the integrity of both the wooden support and paint layers, which have quite different mechanical and physical properties, and hence potential compatibility problems. There have been many different factors of panel degradation over the centuries, such as fire, accidents, vandalism, intentional modifications to adapt them to different display locations or contexts, inappropriate conservation interventions carried out even by well-intentioned restorers and biological degradation e.g. by wood-boring insects, the effects of light and air pollution on paint layers. In addition to these factors significant degradation can be produced by environmental factors - temperature and relative humidity $(\mathrm{RH})$ and their fluctuations - which produce shrinkage/swelling and distortions of the wooden supports and hence may damage the supports themselves (disconnections, permanent distortions, internal stresses, cracks, etc.) and/or the paint layers which usually cannot fully follow the movements of wood. Knowledge of factors that control the climate-induced response of wooden supports enables optimizing decisions about the micro environment, showcases, protections, frames, restoration interventions, and so on. [1] Wood science has been making increasing contributions to the conservation of panel paintings as the necessity for in-depth knowledge of wood as a material has become apparent. Mathematical modelling and experiments on mock-models made of "modern" wood have also been very important and useful tools. However, individual pieces of wood differ from each other; original supports are made of aged wood the story of which is seldom fully known; ground-layers and paintlayers influence the chemical and physical processes involved; therefore a reliable and reasonably accurate knowledge of the behaviour of original panel paintings can only be obtained by measuring and monitoring the original panel paintings themselves. The possibility of undertaking such measurements is constrained by a number of important considerations including: the need to not interfere with the public observing the artwork, to not damage the artwork as well as restricted/limited access to the artwork to install equipment and download data, and, of course, acceptable costs (in terms of both money and time) of the system and its upkeep. Few published papers deal with real-time deformometric monitoring of wooden artworks in a changing climate; among these, [2] and [3] may be cited. Also, selected devices developed towards this purpose have been briefly described in [4], including the Deformometric Kit dealt with in this paper, and in [5].

\section{The "Deformometric Kit"}

The "Deformometric Kit" (DK) is both a methodological approach and an equipment conceived, designed and made at DEISTAF (formerly DISTAF, a Department of the University of Florence). Its main purpose is to carry out measurements and to monitor the deformation dynamics of wooden objects in virtually any environment, for any desired duration (minutes, hours, weeks, years ...), mainly but not exclusively in relation to fluctuations of ambient temperature and humidity. The DK's principle was first tested on a Giotto's panel painting [6]. It was then used again and partly analyzed during further research at DISTAF [7] [8]. The conception of its present configuration has been developed and implemented mainly by the first and last authors of this paper. The DK has been used in several projects, including monitoring original panel paintings during their normal exhibition in museums [9] [10]; monitoring structural replicas in climatic chambers [11] and/or in museum rooms [9]; monitoring boards from Viking ships [12]; evaluating strain induced in painted panels during handling and transportation [unpublished report, see Fig. 6 below]; research on the ageing of wood [13]. This paper describes in greater detail the geometrical principles on which the DK is based, its construction, and its functional parameters.

\subsection{The working principle}


A "base line" perpendicular to the wood grain is chosen on the back of the panel; at its ends two metal "columns" are secured to the wood in such a way that they stand perpendicular to the wood surface (see Fig. 1). The distance between the two columns is measured by means of two displacement transducers, each hinged to the columns at fixed distances from the wood surface. As the panel contracts or expands, the two columns near or move away from each other, and as the panel cups the two columns rotate so that the angle between their two axes changes. As shown in Fig. 1, simple geometrical relationships convey/relate the following parameters: manufacturing and mounting dimensions of the equipment; measurements provided by the transducers (changing over time); expansion/contraction of the wood (occurring along the panel's thickness); cupping of the panel. From these geometrical relationships, several significant parameters can be computed, including cupping angle, curvature radius, expansion/contraction of wood at various depths across the board. Such calculations can be plotted over time, or against other variables, so as to provide a detailed picture of the panel's behaviour. The following parameters appear to be the most significant:

- cupping angle $\boldsymbol{\varphi}$

- length c of the "base line" on the back of the painting (i.e. where the DK is installed)

- length $\mathbf{g}$ of a virtual "base line" on the front of the painting (i.e. where the paint layers were applied)

- variations (expansion or contraction) of the above baselines, here called "elongation", which can be expressed as absolute values $(\mathrm{mm})$ or better as percentage variation $\boldsymbol{\varepsilon}$

The following equations, used to compute the above parameters, have been derived by applying basic geometrical relationships to the schematic diagram shown in Fig. 1, under the hypotheses discussed in $\S 2.1 .1$.
Cupping angle
Radius of curvature
Length of the front baseline
Elongation of front face baseline

$$
\begin{aligned}
& \varphi=2 \cdot \arcsin [(b-a) / 2 \cdot m] \\
& r=(e \cdot z) /(e-b) \\
& g=\varphi \cdot(r+f)
\end{aligned}
$$$$
\varepsilon=\left[\left(g-g_{0}\right) / g_{0}\right]^{*} 100
$$

[radians]
$[\mathrm{mm}]$
$[\mathrm{mm}]$
$[\%]$

The above equations have been entered into a spreadsheet named MK (from the Italian name "Maschera Kit"), which is used to process the downloaded data, and plot the resulting graphs, such as those in Figures 4, 5, 6.

\subsubsection{Notes concerning the assumed geometry of the DK}

The DK is usually mounted to measure the most significant deformations of a panel, which are typically "cupping" and expansion/contraction perpendicular to the wood grain. However, deformations in other directions can also be measured by means of the same principle and equipment. The following hypotheses are assumed to be true, at least for the area where the measuring system is mounted (see also Fig. 1): (a) the measured deformations and the geometrical axes of the DK elements all lie in the same plane perpendicular to the wood grain; (b) the "columns" are tightly connected to the boards and remain perpendicular to their surface in the mounting point at all times; (c) the shape of the cupped board may be considered approximately as an arc of a circle; (d) the boards forming the panel are of constant thickness, which does not vary over time; (e) in the cross-section of the boards, straight lines remain straight even during deformation, and straight lines originally perpendicular to the wood surface remain perpendicular even during deformation.

Experience and a further analysis show that in most cases hypotheses (a) (b) and (c) can be considered true, and associated errors may be neglected with good approximation. Hypotheses (d) and (e) are not essential for the basic geometry of the DK, and are required only for extrapolating measurements to compute deformations of the painted face. As for (d), in real situations the boards can feature different degrees of thickness in different points, and the wood does shrink and swell along the panel's thickness as well. As for (e), further analysis shows that due to wood 
anisotropy some distortion takes place in the cross-section, unless the board was perfectly quarter and, if needed, could be corrected by means of basic but complicated calculations, requiring knowledge of the direction of growth rings. This paper does not consider these errors as the authors intend analyzing and quantifying the errors deriving from deviations from hypotheses (d) and (e) in a subsequent paper..

\subsection{The equipment}

\subsubsection{Components}

The DK can be designed and manufactured to fulfil various needs, in various situations and to pursue various measurement objectives. The most typical configuration is described here, and consists of the following components (see Fig. 2 and 3 ):

(a) Two identical displacement transducers, of the potentiometric type (Note: the potentiometric type was chosen mostly because of its low cost and low energy consumption, enabling a selfstanding system, with very long battery life, to be assembled).

(b) Prolonged, as needed, by aluminium threaded rods, equipped with blocking nuts, allowing for length adjustment. Each transducer "line" (i.e. transducer + connecting pieces + rods) terminates at each end with a steel ball joint, enabling free rotation at connections with "columns".

(c) Two identical "columns", also made of aluminium, with a larger base to be fixed (by means of screws or other devices) on the back face of the panel. Distances between ball joints and wood surface are maintained constant by means of spacers.

(d) A self-powered data-logger, which powers the transducers, reads them and records data with desired frequency (typically every 15/30 minutes).

The equipment is designed so that any small offset of the columns' axes from the plane (caused, for instance, by panel twisting) can occur without damaging the equipment nor significantly affecting the measurements.

\subsubsection{Mounting the DK}

The bases of the columns need to be firmly fixed against and perpendicular to the wood's surface. However such fixation must not cause any significant damage to the panel and, most of all, it must be acceptable to the panel's curator. In several cases three stainless steel panel screws, $3 \mathrm{~mm}$ diameter, 20-25 mm length, provided satisfactory fastening on poplar panels, where the wood density is about $0.4 \mathrm{~g} / \mathrm{cm}^{3}$ and no pre-boring is needed; when the screws are removed, almost no trace remains in the panel. In other cases (e.g. panels made of oak, wood density around 0.8 $\mathrm{g} / \mathrm{cm}^{3}$ ), small blocks of plywood were glued onto the back of the panel (more precisely, Japanese paper was glued to the panel by means of alimentary jelly, and plywood blocks were glued onto the paper by means of a quick set vinyl glue), then the DK's bases were screwed on these blocks; when monitoring is complete, blocks can be easily chopped up by the restorer, and the jelly layer moistened and removed (Jean-Albert Glatigny, personal communication, 2011).

\subsubsection{Setting the data logger}

Transducer outputs are fed into a 2- or 4-channel data-logger, which cyclically reads all the channels at preset intervals (typically every 15/30 minutes for long-duration monitoring; or up to every 1 second / 1 minute for short-duration monitoring, such as during handling); two or four readings are performed at intervals of a few milliseconds, in practice at the same moment. Typically at least one 2-external-channels data-logger is used, which records two transducers plus air temperature and relative humidity at the same preset intervals. The system (transducers + datalogger) is powered by an internal timer at preset intervals only, when measurements are to be recorded; this allows for quite a long battery life, typically over 6 months - incidentally, one year is the shortest period recommended by present EN guidelines [14] for monitoring and characterizing 
the micro-climate surrounding a work of art made of hygroscopic material such as wood. The datalogger's memory fills up over a varying range of time, depending on the preset sampling frequency. For example, a $64 \mathrm{kB}$ memory in a 4-channel data-logger with a sampling frequency of 15 minutes, fills up and hence data need to be downloaded at approximately 96 -day intervals. The recorded data can typically be downloaded by means of a USB cable connection; some loggers that transmit data by radio are being considered.

\subsection{Accuracy of the DK measurements}

Given the complexity of the measurements taken with the DK, their accuracy is hard to assess, both theoretically and practically, and in any case depends on the DK's geometry. Some work is presently ongoing at LMGC (Montpellier, France) where different measurement systems are being compared (Agnès Rouard, personal communication, 2011) under the supervision of one of the authors. However, a general approach showing the influence of the DK's geometry is presented in the following paragraphs.

\section{Systematic errors}

Monitoring mainly implies comparing the values successively attained by the measured parameters; therefore, the possible systematic errors (e.g. inaccuracies in construction and mounting, or in determining calibration factors) tend to affect successive measurements in the same way, so that the trend and shape of resulting diagrams are not significantly affected. To summarize, accuracy is often less important than repeatability, since in most cases differences and variations are the most significant results.

\section{Accidental errors}

The accuracy of the results (i.e. of the parameters resulting from the calculations performed by the MK, after it has processed the raw data provided by the transducers) is strongly affected by both the transducer's errors and the DK's geometry, as shown by the calculation in Annex, which in summary provides the results briefly discussed in the following $\S 2.4$.

\subsection{Influence of design parameters on accuracy and resolution of the DK measurements}

From the calculations in Annex one can derive the following guidelines for choosing design parameters that optimize the DK's performance (accuracy and resolution):

- $\quad$ high precision transducers

- high precision and resolution data-logger

- large distance $\mathbf{m}$ between the transducers

- small distance $\mathbf{z}$ between the lower transducer and the back face of the panel

- large initial (i.e. mounting) distance $\mathbf{e}_{0}$ between the two columns

Furthermore, the performance of the DK will be influenced, inter alia, by the following factors:

- thickness of the panel (the thicker the panel, the less accurate the DK in relation to the measurements extrapolated on the front face)

- calibration accuracy of the individual transducers.

It should therefore be emphasized that the above parameters can be different for each individual DK, so that trying to characterize all DKs by means of one general figure, expressing their accuracy or resolution, would be meaningless. Table 1 in Annex shows the geometrical data and the resulting accuracies (estimated maximum errors) and resolutions (see $\S 2.5$ below) which can be obtained from five actual case-studies. In summary, the following accuracies (maximum estimated errors) were found; figures in parentheses refer to one case, where high precision calibration (HPC) was made:

- accuracy of the individual transducer lines (transducer + data-logger + calibration): ranging between approx. \pm 60 and \pm 110 microns (HPC: \pm 9 )

- accuracy of variation of cupping angle: ranging between approx. \pm 60 and \pm 110 thousands of a degree (HPC: \pm 15$)$ 
- accuracy of elongation of the back face: ranging between approx. \pm 60 and \pm 70 microns (HPC: \pm 14 )

- accuracy of elongation of the front face: ranging between approx. \pm 90 and \pm 140 microns (HPC: \pm 19 ) accuracy of percent elongation of the front face: ranging between approx. $\pm 0.017 \%$ and $\pm 0.022 \%$ (HPC: $\pm 0.005 \%$ ).

\subsection{Resolution of the DK measurements}

Since the resolution of the transducers is virtually infinite, the resolution of the displacement readings depends on the resolution of the data-logger. With the equipment which has mostly been used (see $\S 2.2 .1$ ), such resolution is 7.3 microns (see Annex $\S \mathrm{C}$ ). The resolution of the whole DK depends both on the resolution of transducers and data-loggers, and on the DK's geometry and dimensions. Resolution values for the same actual study cases as in $\S 2.4$ are also reported in Annex, Table 1.

\section{Application examples}

In order to show configurations and resulting data, some examples are briefly outlined in Figures 4, 5 and 6 , which all refer to data obtained from DKs mounted on the back face of original panels exhibited in a hall (Sala dell'Ospizio) of the San Marco museum, Florence, Italy. Fig. 4 shows data measured (temperature and relative humidity of the surrounding air) and calculated from DK's measurements (cupping angle $\boldsymbol{\varphi}$ and elongation of front face $\boldsymbol{\varepsilon}$ ) plotted against/over time. The time period shown starts in June 2008 and ends in November 2009 (approximately 17 months). Data were recorded every 15 minutes. To make them more distinct, the plots show data smoothed by a 6-hour moving average. The yearly cycle of the surrounding climate and of the panel's deformations is clearly visible, together with a surprisingly prompt and accurate deformational response of the panel (inverse relationship between $\mathrm{RH}$ variations and the panel's cupping angle). Analysis (not discussed here) confirms that such deformations originate from the formation of moisture gradients along the panel's thickness, particularly when such gradients are asymmetric due to the presence of paint layers only on the painted face of the panel. These are transient deformations that fade over time; however, in a real museum environment the climatic fluctuations never cease, and the diagrams clearly show the continuously changing deformation of the panels, which constantly adapt themselves to the changing environment, and are never in a state of equilibrium in terms of uniform moisture and temperature distribution across their structure. In order to show with greater detail the daily variations and the prompt deformational response, a 10day period from the data of Fig. 4 is shown in Fig. 5.

Fig. 6 shows quite a different application of the DK, that is monitoring the handling operations of an original panel painting (Case 2 in Table 1 in Annex), and its effects on the panel strains. To enable a detailed analysis, data were recorded every minute, and no smoothing was performed on the resulting plot. The order of magnitude of the strains produced by handling can be well identified. Also the different deformations pertaining to the two resting positions (leaning and vertical) are highlighted. The jolts visible on the two plots highlight the resolution limit of the equipment, respectively $\sim 0.01$ degrees for $\boldsymbol{\varphi}$ and $\sim 0.011 \%$ for $\boldsymbol{\varepsilon}$, (see Table 1 in Annex).

\section{Final comments}

\section{$\underline{4.1 \text { Usefulness of the DK }}$}

In sum, the Deformometric Kit is a stand-alone device, equipped with electronic data logger and probes measuring temperature and relative humidity, specially conceived to perform long-term and/or short-term monitoring of the deformational response of painted panels. Monitoring can be carried out in nearly any environment, and for any desired duration (minutes, hours, weeks, years...). The only significant requirement is that some space, of the order of $8-12 \mathrm{~cm}$, be available 
behind the panel (e.g. distance from the wall). It is not invasive, either from a technical point of view (no damage to the panel), or from an aesthetical point of view (no interference with visitor experience). It provides reliable and significant data showing the history of the panel's deformation under the influence of factors such as environmental fluctuations, handling or transportation. It can therefore be considered a new, powerful method for studying the deformational response of panel paintings and other cultural wooden objects. The reliable and reasonably accurate knowledge of the behaviour of individual, original panel paintings placed in their usual display locations, enables evaluating the impact of climate on their conservation, helps to make decisions for future restoration interventions, and provides reference data for calibrating and validating numerical models.

\subsection{Comments about use and potential developments of the DK}

To study the reactions of a panel to the fluctuations of its surrounding environment, it is necessary to cover at least a one-year period of monitoring, according to present technical guidelines [14]. It should be emphasized that the measurements obtained by means of the DK only represent the behaviour of the board(s) at the location in which the equipment has been installed; this location, therefore, must be chosen accurately, and in accordance with monitoring objectives. Experience shows that each and all details in manufacturing and installing the DK are essential for obtaining reliable results. Firmness and stability of both mechanical and electrical connections require special care, in order to prevent loss of performance of the electrical contacts and the undesirable onset of relative movements among the mechanical parts, leading to deteriorated and hence unusable data. Moreover, at the present time, analysis of the data requires demanding commitment from a well-trained researcher. Possible future developments of hardware and software will enable routine examination of the main data by personnel that are not so highly trained; however, in-depth exploitation of the data should remain the realm of well-trained researchers. Further research needs to be carried out on the accuracy of the measurements, as influenced by several factors, including the DK's geometry and the anisotropy of wood shrinkage/swelling.

\section{REFERENCES}

[1] B. Knight, D. Thickett, Determination of response rates of wooden objects to fluctuating relative humidity in historic properties, in T. Padfield, K. Borchersen (Eds.) Museum Microclimates, Copenhagen, 2007 ISBN 978-87-7602-080-4

[2] L. Bratasz, R. Kozlowski, D. Camuffo, E. Pagan, Impact of indoor heating on painted wood: monitoring the altarpiece in the church of Santa Maria Maddalena in Rocca Pietore, Italy, Studies in Conservation, 52, 3 (2007), pp. 199-210

[3] J. Colmars, Hygromécanique du matériau bois appliquée à la conservation du patrimoine culturel: étude sur la courbure des panneaux peints [Wood hygro-mechanical behaviour in relation to the conservation of cultural heritage: discussion about panel painting cupping], Ph.D. thesis, University of Montpellier 2, France, 2011

[4] P. Dionisi-Vici, J. Colmars, L. Uzielli, Instrumentations pour le contrôle continu des panneaux peints en bois [Instrumentation for monitoring painted wooden panels], Technè 29 (2009), 21-27, ISSN 1254-7867

[5] L. Uzielli, P. Dionisi-Vici, J. Gril, Caractérisation physico-mécanique du support [physicalmechanical characterization of the wooden support], in: J.P Mohen, M. Menu, B. Mottin (Eds.), Au coeur de la Joconde [In the heart of the Mona Lisa], Gallimard, 2006, Musée du Louvre, Paris, 5255 (ISBN 2-35031-066-3 / 2-07-011833-9).

[6] L. Uzielli, M. Fioravanti, O. Casazza, G. Perucca, A technique for double-sided monitoring the deformations of the wooden supports of panel paintings: the experience of Giotto's "Maestà di 
Ognissanti", in: A. Guarino (Ed.), Proceedings of the 3rd International Conference "ART '92",

[7] O. Allegretti, Sviluppo e caratterizzazione di metodologie per la misurazione delle variazioni dimensionali dei dipinti su tavola [Development and characterization of methods for measuring the dimensional variations of panel paintings], Ph.D. thesis, University of Florence, Italy, 1998

[8] P. Dionisi-Vici, Sviluppo di un apparato per la misurazione di forze e deformazioni indotte nei dipinti su tavola da variazioni climatiche: la Traversa Strumentata [Development of an apparatus to measure forces and deformations induced in panel paintings by climatic variations: the Monitoring Crossbeam], Ph.D. thesis, University of Florence, Italy, 1999

[9] P. Dionisi Vici, I. Bucciardini, M. Fioravanti, L. Uzielli, Monitoring climate and deformation of panel paintings in San Marco (Florence) and other museums, in: L. Uzielli (Ed.), Proceedings of the International Conference held by COST Action IE0601 in Florence (Italy), 8-10 November 2007, Firenze University Press, ISBN 978-88-8453-382-1 (print), ISBN 978-88-8453-396-8 (online)

[10] P. Dionisi-Vici, M. Formosa, J. Schiro, L. Uzielli, Local deformation reactivity of panel paintings in an environment with random microclimate variations: the Maltese Maestro Alberto's Nativity case-study, in: J. Gril (Ed.), Proceedings of the International Conference held by COST Action IE0601 Braga - Portugal, 5-7 November 2008, Firenze University Press, ISBN 978-88-6453-157-1 (print), ISBN 978-88-6453-165-6 (online)

[11] P. Dionisi-Vici, P. Mazzanti, L. Uzielli, Mechanical response of wooden boards subjected to humidity step variations: climatic chamber measurements and fitted mathematical models, J. of Cult. Her. 7 (2006), 37-48

[12] P. Dionisi-Vici, M. Jensen, B. Aarseth, J. Bill, S. Braovac, G. Hjulstad, R. Løchen, E. Storbekk, First analytical results of the measurement of responses in archaeological wood to ambient temperature and relative humidity: a case study from the Oseberg ship, Poster at 4th International Conference of COST Action IE0601, Izmir, Turkey, 20-22 October 2010

[13] J. Froidevaux, M. Müller, R. Kühnen, M. Fioravanti, L. Uzielli, J. Gril, P. Navi, 3D modelling of hydral deformation of panel paintings and its confirmation by the experiments, Poster at 4th International Conference of COST Action IE0601, Izmir, Turkey, 20-22 October 2010

[14] EN 15757:2010 - Conservation of Cultural Property - Specifications for temperature and relative humidity to limit climate-induced mechanical damage in organic hygroscopic materials

\section{ACKNOWLEDGEMENTS}

The authors gratefully acknowledge the support and cooperation offered by many friends and colleagues from several institutions, including the following:

- Marco Fioravanti and Giacomo Goli from DEISTAF, University of Florence, Italy

- Alfredo Canacci, Master Turner from Florence, Italy, for providing suggestions and for manufacturing the non-commercial components

- Joseph Gril, Julien Colmars, Bertrand Marcon, Agnès Rouard, from LMGC, University of Montpellier 2, France, for their cooperation in this research

- Roman Kozlowski, Lukasz Bratasz, Michal Lukomski, from the Institute of Catalysis and Surface Chemistry, Polish Academy of Sciences, Cracow, Poland, for accurately reading and suggesting improvements to the draft of this paper

- Magnolia Scudieri (Director of the San Marco museum, Florence, Italy), and Antonia d'Aniello (Superintendent at Lucca, Italy), for encouraging this research, and authorizing the mounting of several DKs on artworks displayed in their museums

- Marco Ciatti, Ciro Castelli and Andrea Santacesaria, from OPD (Florence, Italy), and Daniele

Piacenti, freelance Restorer, for their constructive comments and their friendly support 
- Jean-Albert Glatigny (panel's Master Restorer in Brussels, Belgium) and Jonathan Graindorge Lamour (student at INP - Institut National du Patrimoine, France) for cooperating in developing a securing system for DK on Flemish oak panels

- Susan Braovac from museum of Cultural History, University of Oslo, for hosting P. Dionisi-Vici's STSMs in Oslo, and supporting the use of DKs to study deformational behaviour of the Viking ship planks

- Michael Formosa, Joseph Schiro, Claire Baluci from Heritage Malta, for hosting P. Dionisi-Vici's STSMs in Malta, and cooperating in related research.

Several of the activities mentioned in this paper have been made possible by cooperation developed within COST Action IE0601 "Wood Science for Conservation of Cultural Heritage", which also financially supported some STSMs (Short Term Scientific Missions) intended to disseminate the DK's applications.

\section{SUPPLIERS}

Data-loggers: Hobo U12-013 (temperature, RH, 2 external channels), U12-006 (4 external channels), Onset Computer Corporation (USA). Linear displacement sensors SLS095/0030/1.2K/R/50, Penny \& Giles Controls Ltd. (UK). Digital caliper used for calibration of transducer lines: Mitutoyo Digimatic, 550 series, $600 \mathrm{~mm}$. Manufacturing drawings of components not commercially available, as well as the MK spreadsheet, can be obtained from the authors at DEISTAF, the University of Florence. 


\section{FIGURE CAPTIONS}

Fig. 1 - Schematic diagram of the main geometrical parameters of the DK. The convention concerning positive (front face convex) and negative (front face concave) values of the cupping angle $\varphi$ is also shown.

Key to symbols:

a distance between the axes of the two columns, at distance $\mathbf{m}+\mathbf{z}$ from the back face of panel, as measured by the upper transducer (variable in time)

b distance between the axes of the two columns, at distance $\mathbf{z}$ from the back face of the panel, as measured by the lower transducer (variable in time)

c length of the baseline (assumed to be an arc of a circle), lying on the back face of the panel, joining the axes of the two columns (variable in time)

e distance between the axes of the two columns, where they intersect the back face of panel (variable in time)

f thickness of the wooden panel (assumed constant)

g length of the virtual baseline (assumed to be an arc of a circle), lying on the front (painted) face of the panel, joining the axes of the two columns (variable in time)

$\mathbf{g}_{\mathbf{0}} \quad$ reference value of $\mathbf{g}$ (typically the value of $\mathbf{g}$ at the start of the monitoring)

$\mathbf{m}$ distance between the centres of the ball joints of the two transducers on the same column (constant, determined by construction)

$\mathbf{r} \quad$ radius of curvature of the baselines (variable in time)

$\mathbf{z}$ distance between the centre of the ball joint of the lower transducer, and the back face of the panel, along the axis of the column (constant, determined by construction)

$\varphi \quad$ "cupping angle" between the axes of the two columns (assumed to be coplanar) (variable in time) (radians)

Fig. 2 - A simplified construction drawing of a DK, in actual scale, mounted on a flat panel (deformation and cupping might intervene later).

Key to symbols:

h height of columns (in this drawing: $70 \mathrm{~mm}$ ); in order to house the device, the distance behind the panel should be larger than $h$

$\mathbf{z}$ distance between the centre of the ball joint of the lower transducer, and the back face of the panel, along the axis of the column (in this drawing: $14.5 \mathrm{~mm}$ )

m distance between the centres of the ball joints of the two transducers on the same column (in this drawing: $33 \mathrm{~mm}$ )

d transducer's shaft displacement (with this type of transducer, the measuring range is approximately between $\mathrm{d}=3$ and $\mathrm{d}=33 \mathrm{~mm}$ )

$\mathbf{e}_{0}$ distance between the axes of the two columns, where they intersect the back face of panel, at time of mounting (in this drawing: $224 \mathrm{~mm}$ )

1 rod end spherical bearing (ball joint $\varnothing 6 \mathrm{~mm}$ )

2 fitting, connecting transducer's back end to the back spherical bearing

3 lower transducer (also named "b")

4 upper transducer (also named "a")

5 extension rod, connecting the transducer's shaft to the rod end spherical bearing

6 rod end spherical bearing (ball joint $\varnothing 6 \mathrm{~mm}$ )

7 base, connecting the column to the wooden panel $(\varnothing 30 \mathrm{~mm}$, with 6 holes $\varnothing 3 \mathrm{~mm}$ for at least 3 panel screws)

8 spacer

9 column

Fig. 3 - A DK mounted on the back face of the original panel "Trittico di San Pietro Martire" ( 1425), exhibited in a hall (Sala dell'Ospizio) of San Marco museum, Florence, Italy. The panel is made of poplar (Populus alba L.) wood boards, $28-30 \mathrm{~mm}$ thick 
Fig. 4 - Data measured (temperature and relative humidity of the surrounding air) and calculated (cupping angle $\boldsymbol{\varphi}$ and elongation of front face $\boldsymbol{\varepsilon}$ ) from a DK placed on the "Trittico di San Pietro Martire", plotted against time.

The time period shown starts in June 2008 and ends in November 2009 (approximately 17 months).

Fig. 5 - A 10-day period in the data of Fig. 4, showing daily variations more clearly.

Fig. 6 - Monitoring the handling of an original panel painting ("Pala del Bosco ai Frati" 1450-52, by Beato Angelico, San Marco museum, Florence, Italy), from a leaning position on a trolley, to its vertical exhibition position, on the wall. 

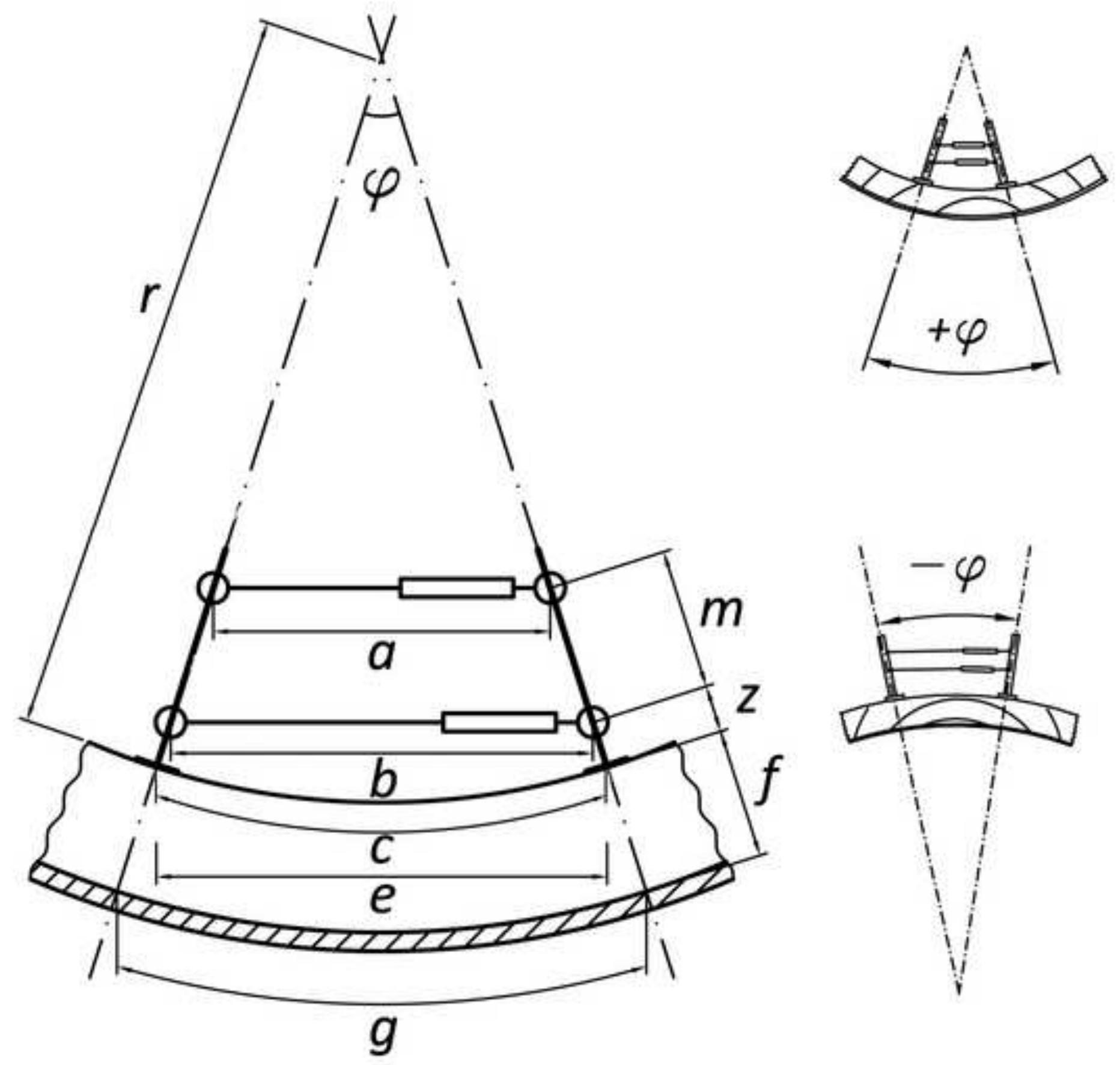


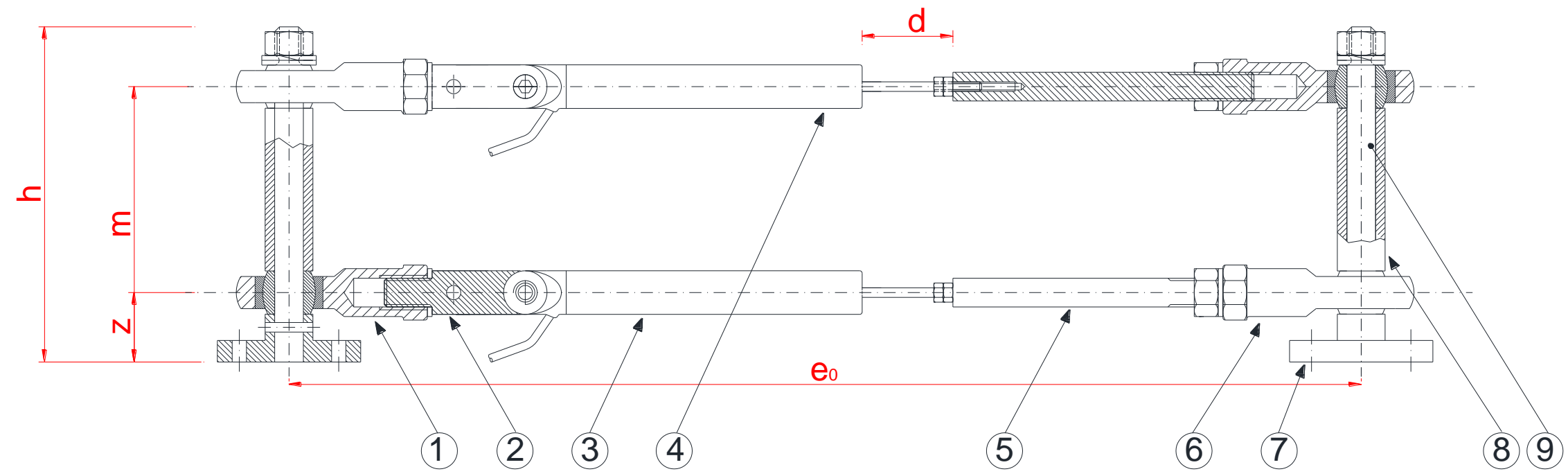



Click here to download high resolution image
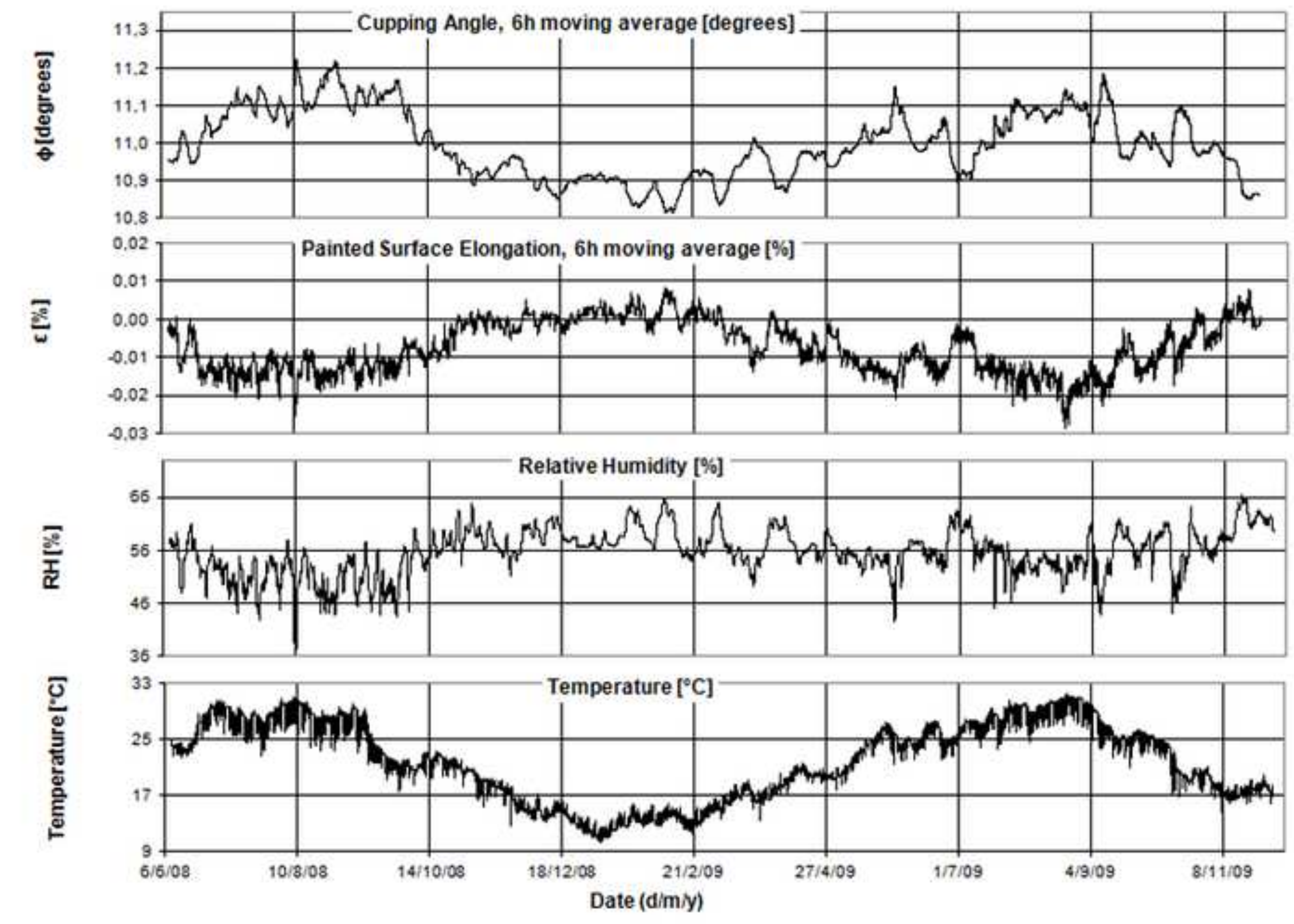

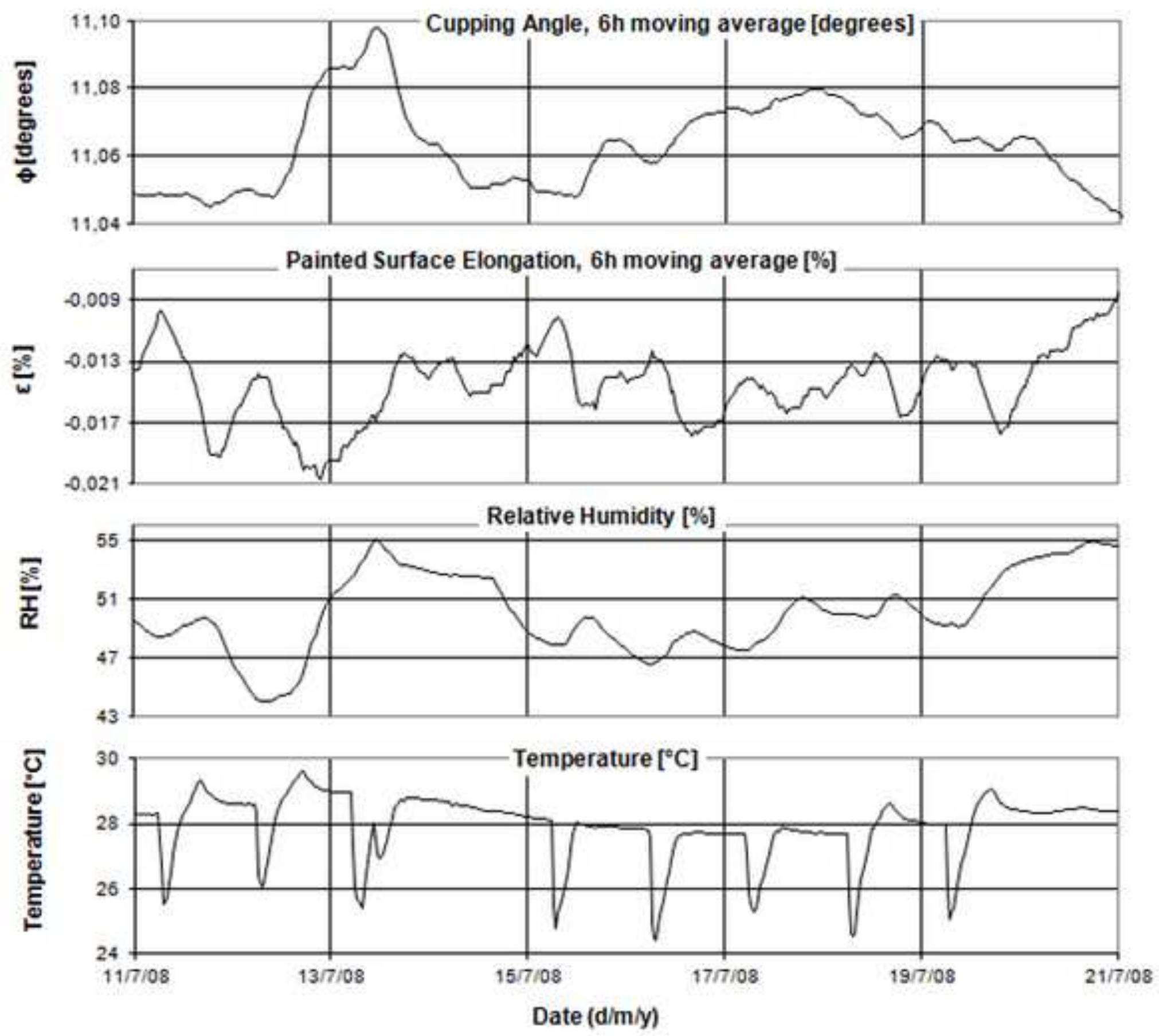
Click here to download high resolution image

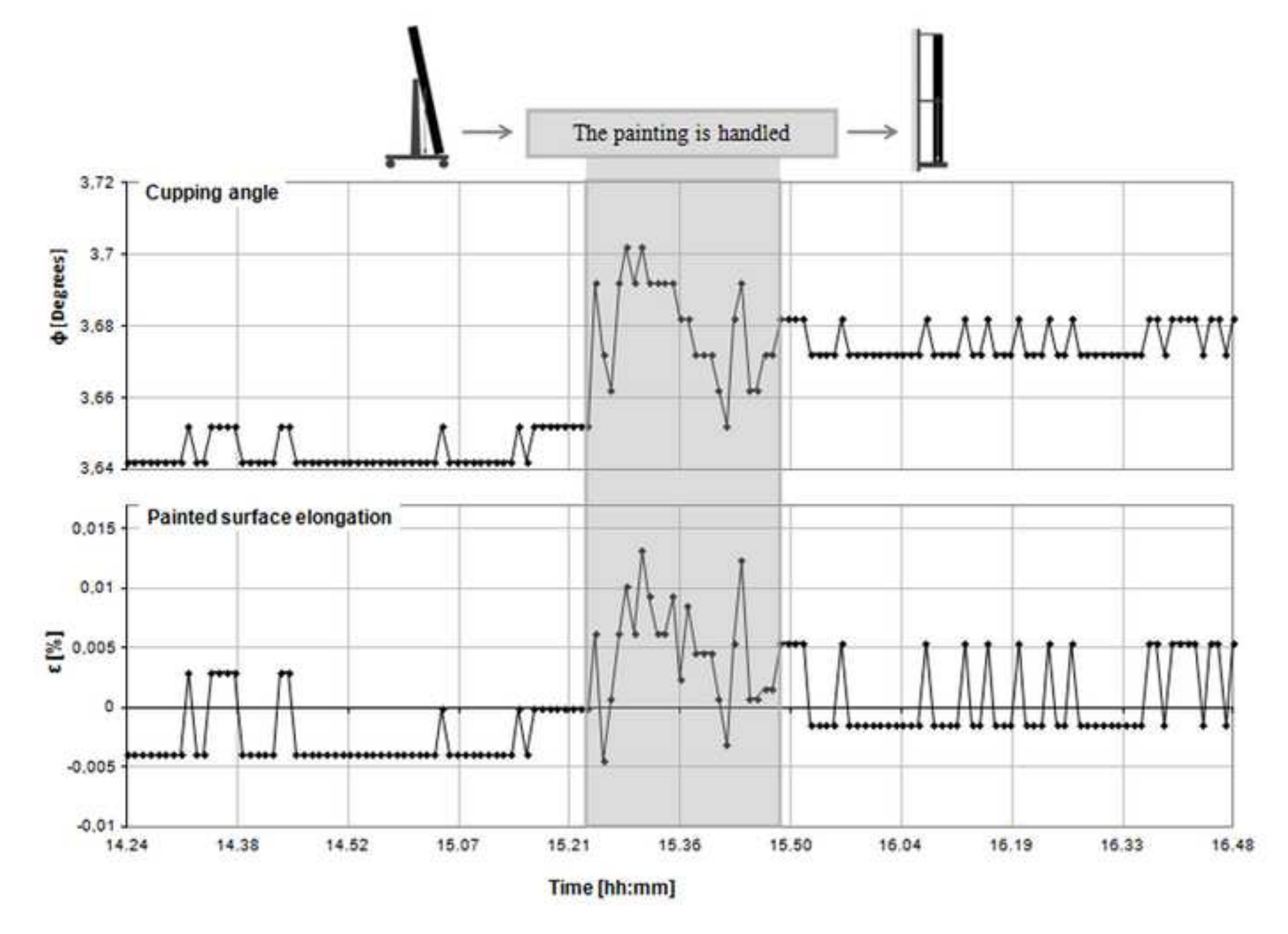


((Note: this Annex will be treated as "supplementary material", i.e. it will not be printed, but will be made available online as a PDF file))

\section{ANNEX - Estimation of how the DK's geometry affects the propagation of errors, and hence the criteria for designing individual DK applications.}

In the DK, we need to consider the resolution and accuracy both of the individual transducers, and the whole DK (including the MK calculations) considered as one measuring system.

\section{A) Accuracy of individual transducers}

The data sheet of the potentiometric transducers (see $\S$ "Suppliers" at the end of the referred paper), specifies that, regardless of the stroke length, their "resolution" is virtually infinite, and "hysteresis (repeatability)" is less than $0.01 \mathrm{~mm}$. For $30 \mathrm{~mm}$ stroke length (the most used in the DKs described in this paper) "independent linearity" is given as $\pm 0.25 \%$ (i.e. $\pm 0.0025 \cdot 30= \pm 0.075$ $\mathrm{mm}= \pm 75 \mu \mathrm{m})$. Moreover, the actual accuracy of the transducers in DKs depends on the accuracy of the data-loggers used to read them. The data sheets of the data-loggers (see again $\S$ "Suppliers" at the end of this paper) specify that the accuracy of external input channels is $\pm 2 \mathrm{mV} \pm$ $2,5 \%$ of absolute reading. However, further inquiries clarified that some part of such inaccuracies (approximately $\pm 2 \%$ ) can be considered systematic and held constant for each individual instrument, while other parts depend on random errors and on the instrument's resolution. Finally, the data sheet of the $600 \mathrm{~mm}$ digital calliper used for calibration of the transducer lines (see below) states that the resolution is $\pm 0.01 \mathrm{~mm}$, and the error is $\pm 0.05 \mathrm{~mm}$.

Combining the above accuracies, each in its "worst case", would lead to an accuracy (or rather "inaccuracy") of the whole system much larger than would be acceptable for the measurements to be performed; moreover, inaccuracy would be much larger than what was found when calibrating the individual transducer lines. In fact a calibration procedure is performed once for all before each DK is installed, by comparing the electrical readings (on the same data-logger and channel actually used for monitoring) with the actual displacement (measured with the $600 \mathrm{~mm}$ calliper, resolution $\pm 0.01 \mathrm{~mm}$ ); the calibration factor is obtained for each individual combination of transducer-andchannel, by interpolating the measured points with a straight line, by the least squares method. Global accuracy for each calibration is then computed as the maximum difference between the actual measurement and the corresponding straight line value. By the above described calibration procedure (which, on the whole, accounts for inaccuracies of the transducers, the data-loggers, the calibration calliper, and the possible relative movements among the mechanical parts forming the transducer lines), the global accuracy for individual combinations of transducer-and-channel was found to be of the order of $0.04 \mathrm{~mm}=40 \mu \mathrm{m}$ for the DKs used both in museums and in the laboratory in Florence, and of the order of $0.009 \mathrm{~mm}=9 \mu \mathrm{m}$ for the DKs used in the laboratory in Montpellier; such values have therefore been used to calculate the accuracies reported in Table 1.

\section{B) Accuracy of the whole DK}

The accuracy of the whole DK (including the MK calculations), considered as one measuring system, is affected by (1) the accuracy of transducers, (2) the DK's ideal geometry (as described in Fig. 1), (3) inaccuracies in construction, in mounting, and in functioning of the mechanical joints, and (4) by the electronic circuits used to read the transducers. The two latter factors depend on construction accuracy and choice of components, and their discussion is beyond the scope of the present paper. This section deals with the first two factors, which can be considered as prevailing: - how the transducer's accuracy and the DK's design parameters affect the accuracy of the whole DK's measurements, and - hence, the effect of individual design parameters on the DK's performance. 
Such values are then used to calculate the accuracies reported in Table 1

A short explanation of the symbols used:

- $\quad " \Delta$ " represents the error, i.e. the difference between the measurement result and the true value of the measured quantity;

- "d" represents the differential, i.e. a very small variation of the measured quantity (e.g. da, db, dg etc.);

- $\quad$ " $\Delta \mathrm{d}$ " represents therefore the error on the variation of the concerned quantity, be it a reading or the result of a calculation (e.g. $\Delta$ da is the possible error of the reading of transducer "a"; $\Delta \mathrm{d} \boldsymbol{\varphi}$ is the propagated error of the cupping angle $\boldsymbol{\varphi}$ );

- since the two transducers are identical, we can assume that also their possible errors are also identical, hence $\Delta \mathbf{b}=\Delta \mathbf{a}$ and $\Delta \mathrm{d} \mathbf{b}=\Delta \mathrm{da}$.

B1) Influence of the transducer's possible errors $(\Delta \mathbf{a}, \Delta \mathbf{b})$ and of the construction parameter $\mathbf{m}$ on the error $(\Delta \mathrm{d} \varphi)$ for the variation of the cupping angle $\mathrm{d} \varphi$

From equation (1) in $\S 2.1$, the following equation can be obtained:

$$
\sin (\boldsymbol{\varphi} / 2)=(\mathbf{b}-\mathbf{a}) /(2 \cdot \mathbf{m})
$$

Since $\mathbf{m}$ is a constant, deriving such an equation with respect to time yields:

$$
(1 / 2) \cdot \cos (\varphi / 2) \cdot d \varphi=(d b-d a) /(2 \cdot m)
$$

and hence:

$$
\mathrm{d} \boldsymbol{\varphi}=(\mathrm{d} \mathbf{b}-\mathrm{da}) /(\mathbf{m} \cdot \cos (\boldsymbol{\varphi} / 2))
$$

Since $\varphi$ is small, we can assume $\cos \varphi \approx 1$

The most unfavourable situation entails the summation of the modules of the errors:

$$
\Delta \mathrm{d} \boldsymbol{\varphi}=(\Delta \mathrm{d} \mathbf{b}+\Delta \mathrm{d} \mathbf{a}) / \mathbf{m}=2 \cdot \Delta \mathrm{d} \mathbf{a} / \mathbf{m}
$$

The error $(\Delta \mathrm{d} \varphi)$ on the variation $(\mathrm{d} \varphi)$ of the cupping angle $\boldsymbol{\varphi}$ is therefore:

- proportional to the error of the linear measurements provided by the transducers $(\Delta \mathrm{da}$ or $\Delta \mathrm{db})$

- inversely proportional to the design parameter $\mathbf{m}$ (distance between the two transducers)

B2) Influence of the transducer's possible errors $(\Delta \mathrm{da}=\Delta \mathrm{db})$ and of the construction parameters $\mathbf{z}$ and $\mathbf{m}$ on the error $(\Delta \mathrm{d} \mathbf{c})$ of the back face baseline's (c) elongation

From equation [2] in $\S 2.1$, the following equation can be obtained:

$$
(\mathbf{e}-\mathbf{b}) / \mathbf{z}=(\mathbf{b}-\mathbf{a}) / \mathbf{m}
$$

Since $\mathbf{m}$ and $\mathbf{z}$ are constants, deriving such an equation with respect to time yields:

$$
\begin{aligned}
& (\mathrm{de}-\mathrm{d} \mathbf{b}) / \mathbf{z}=(\mathrm{d} \mathbf{b}-\mathrm{d} \mathbf{a}) / \mathbf{m} \\
& \mathrm{de}=[1+(\mathbf{z} / \mathbf{m})] \cdot \mathrm{d} \mathbf{b}-(\mathbf{z} / \mathbf{m}) \cdot \mathrm{d} \mathbf{a}
\end{aligned}
$$

The most unfavourable situation entails the summation of the modules of errors:

$$
\Delta \mathrm{de}=[1+(\mathrm{z} / \mathrm{m})] \cdot \Delta \mathrm{db}+(\mathrm{z} / \mathrm{m}) \cdot \Delta \mathrm{da}
$$


The two transducers are identical, hence we can assume $\Delta \mathrm{db}=\Delta \mathrm{da}$

$$
\Delta \mathrm{de}=\{[1+(\mathbf{z} / \mathbf{m})]+(\mathbf{z} / \mathbf{m})]\} \cdot \Delta \mathrm{da}=[1+2 \cdot(\mathbf{z} / \mathrm{m})] \cdot \Delta \mathrm{da}
$$

In situations where the DK is used, the difference between chord $\mathbf{e}$ and arc of circle $\mathbf{c}$ is typically very small, hence $\Delta \mathrm{de} \approx \Delta \mathrm{dc}$, therefore

$$
\Delta \mathrm{d} \mathbf{c}=[1+2 \cdot(\mathrm{z} / \mathrm{m})] \cdot \Delta \mathrm{da}
$$

The error $(\Delta \mathrm{d} \mathbf{c})$ on the variation of the elongation $(\mathrm{dc})$ of the back face baseline $\mathbf{c}$ is therefore:

- proportional to the error in the linear measurements provided by the transducers ( $\Delta$ da or $\Delta \mathrm{db})$

- $\quad$ proportional to the design parameter $\mathbf{z}$ (distance between the lower transducer and the back face of the panel)

- inversely proportional to the design parameter $\mathbf{m}$ (distance between the two transducers)

B3) Influence of the transducer's measurement errors $(\Delta \mathrm{da}=\Delta \mathrm{db})$ and of the construction parameters $\mathbf{z}$ and $\mathbf{m}$ on the error $(\Delta \mathbf{d g})$ of the front face baseline's $(\mathbf{g})$ elongation.

By performing similar calculations as in case (B2) above, we obtain:

$$
\Delta \mathrm{dg}=\{1+[2 \cdot(\mathrm{f}+\mathrm{z}) / \mathrm{m})]\} \cdot \Delta \mathrm{da}
$$

The error $(\Delta \mathbf{d g})$ on the variation of the elongation $(\mathrm{dg})$ of the front face baseline $\mathbf{g}$ is therefore:

- $\quad$ proportional to the error in the linear measurements provided by the transducers ( $\Delta \mathrm{da}$ or $\Delta \mathrm{db})$

- $\quad$ proportional to the design parameter $\mathbf{z}$ (distance between the lower transducer and the back face of the panel)

- proportional to the thickness $f$ of the panel

- inversely proportional to the design parameter $\mathbf{m}$ (distance between the two transducers)

B4) Influence of the initial distance $\mathbf{e}_{0}$ between the columns (mounting distance) on the percentage error $(\Delta \mathrm{d} \boldsymbol{\varepsilon})$ of the front face baseline's $(\mathbf{g})$ elongation

Carrying out calculations similar to those performed above would lead to quite complicated equations from which the desired results could not be easily derived. A simpler, although rougher approach can be considered as follows. If we consider a uniformly cupped panel (i.e. with the same radius of curvature $\boldsymbol{r}_{0}$ ), increasing the initial distance $\mathbf{e}_{0}$ between the columns entails a larger cupping angle $\boldsymbol{\varphi}_{0}$, such that $\mathbf{e}_{0}=\mathbf{r} \cdot \boldsymbol{\varphi}_{0}$

From Fig. 1, considering the similar triangles: $r / e=(r-z) / b$; hence $\mathbf{e}=\mathbf{b} \cdot \mathbf{r} /(\mathbf{r}-\mathbf{z})$ In order to simplify, if $\mathbf{r}$ remain constant, but the panel undergoes an elongation de:

$$
\mathrm{de}=\mathbf{d b} \cdot \mathbf{r} /(\mathbf{r}-\mathbf{z})
$$

and when $r>>z$ for small values of $\boldsymbol{\varphi}$ we can assume $\mathbf{e} \approx \mathbf{c} \approx \mathbf{b} \approx \mathbf{g}$ and hence de $\approx \mathrm{d} \mathbf{c} \approx \mathrm{d} \mathbf{b} \approx \mathrm{dg}$

However, if we express the elongation as a percentage of its original dimension, we obtain (from equation (4)):

$$
\mathrm{d} \boldsymbol{\varepsilon}=\left[\mathrm{dg} / \mathbf{g}_{\mathbf{0}}\right]^{\star} 100=\left[\mathrm{db} / \mathbf{g}_{0}\right]^{\star} 100 \approx\left[\mathrm{db} / \mathbf{e}_{0}\right]^{\star} 100
$$

and the influence of the error $(\Delta \mathrm{db})$ on the variation of the elongation $(\mathrm{dg})$ of the front face baseline $\mathbf{g}$ is therefore:

$$
\Delta \mathrm{d} \boldsymbol{\varepsilon}=\left[\Delta \mathrm{db} / \mathbf{g}_{0}\right]^{*} 100 \approx\left[\Delta \mathrm{db} / \mathbf{e}_{0}\right]^{*} 100
$$

Therefore we can see that $\Delta \mathrm{d} \boldsymbol{\varepsilon}$ is inversely proportional to $\mathbf{g}_{0}$ i.e. to $\mathbf{e}_{0}$.

\section{C) Resolution of individual transducers}


As reported in $\S \mathrm{A}$ above, the data sheet specifies that the resolution of the transducers is virtually infinite. However, the actual resolution in reading the transducers is given by the resolution of the data-loggers. For instance, for the equipment which has mostly been used (see § 2.2.1):

- the data-logger provides a measuring range of $2.5 \mathrm{~V}$ and a resolution of 12 bits; since $2^{12}=$ 4 096, the reading resolution (1 digit) corresponds therefore to $2500 / 4096=0.61 \mathrm{mV}$

- the transducers have a measuring range of $30 \mathrm{~mm}$

- the reading resolution corresponds therefore to 1 digit $=30 / 4096=0.0073 \mathrm{~mm}=7.3 \mu \mathrm{m}$.

\section{D) Resolution of the whole DK}

Since the final formulas derived above express the propagation of errors through the geometry of the DK, the DK's resolution for each of the computed parameters $(\boldsymbol{\varphi}, \mathbf{c}, \mathbf{g}, \boldsymbol{\varepsilon}, \ldots)$ can also be obtained from such formulas, by replacing the estimated error $\Delta \mathbf{a}$ or $\Delta \mathbf{b}$ with the resolution of the data-logger readings of the transducers. However, such formulas are affected by some approximation, and some results might be inaccurate in some way. Another method, less general but more intuitive and accurate, is the following, applicable for any individual case: if the DK's geometric dimensions are known, the resolution can also be obtained through computing by means of the "Maschera Kit" the output variations produced by inputting a variation of plus or minus 1 digit (by definition, the resolution) of the measurements provided by the transducers (parameters "a" and/or "b") in their most extreme combination. The resolution figures reported in Table 1 have been computed according to this latter method.

\section{Insert Table 1}




\section{TABLE CAPTIONS}

Table 1 - Geometrical data and the resulting measurement parameters for five actual DK casestudies (Case 1: Replica panel, named "A", kept in DEISTAF's climatic chambers. Cases 2-3-4: original panel paintings by Beato Angelico, exhibited in San Marco museum, Florence; 2-"Pala del Bosco ai Frati", 3-“Trittico di San Pietro Martire", 4-“Armadio degli Argenti”. Case 5: test panel in LMGC laboratory, Montpellier).

Key to the headings of the table, and related measurement units:

I - DK's geometric parameters (see Fig. 1):

$\mathbf{e}_{0} \quad$ Mounting distance between the columns

z Distance between the lower transducer and the back face

m Distance between the two transducers

f Thickness of the board

II - Accuracy of the individual transducer lines (transducer + data-logger + calibration) (see $\S$ A) (microns):

$\Delta \mathrm{d} \mathbf{a}=\Delta \mathrm{d} \mathbf{b})$

III - Accuracy of the calculated parameters (see $\S B$ ):

$\Delta \mathrm{d} \varphi$ Accuracy (maximum estimated error) of variation $\mathrm{d} \varphi$ of cupping angle $\boldsymbol{\varphi}$ (thousands of a degree)

$\Delta \mathrm{dc} \quad$ Accuracy (maximum estimated error) of elongation dc of the back face (microns)

$\Delta \mathrm{dg} \quad$ Accuracy (maximum estimated error) of elongation dg of the front face (microns)

$\Delta \mathrm{d} \varepsilon \quad$ Accuracy (maximum estimated error) of percent elongation $\boldsymbol{\varepsilon}$ of the front face (\%)

IV - Resolution of the individual transducer lines (transducer + data-logger) (see § C)

(microns)

V - Resolution of the calculated parameters (see $\S \mathrm{D})$ :

$\varphi \quad$ Resolution of the measurement of variation of cupping angle $\boldsymbol{\varphi}$ (thousands of a degree)

c Resolution of the measurement of length $\mathbf{c}$ of the back face (microns)

g Resolution of the measurement of length $\mathbf{g}$ of the front face (microns)

$\varepsilon \quad$ Resolution of the measurement of percent elongation $\varepsilon$ of the front face (\%)

As mentioned in $\S \mathrm{D}$, the resolutions reported in this Table have been obtained through computing by means of the "Maschera Kit" the output variations produced by inputting a variation of plus or minus 1 digit (by definition, the resolution) of the measurements provided by the transducers ("a" and/or "b") in their most extreme combinations, described below:

- column (i): variation by +1 digit of the input from transducer (a) alone

- column (ii): variation by +1 digit of the input from transducer (b) alone

- column (iii): variation by -1 digit of the input from transducer (a) and by +1 digit of the input from transducer (b) 


\section{Table 1}

\begin{tabular}{|c|c|c|c|c|c|c|c|c|c|c|c|c|c|c|c|c|c|c|c|c|c|}
\hline & \multicolumn{4}{|c|}{ I } & II & \multicolumn{4}{|c|}{ III } & \multirow[t]{2}{*}{ IV } & \multicolumn{11}{|c|}{ V } \\
\hline \multirow{3}{*}{ Case } & $\mathbf{e}_{0}$ & z & $\mathbf{m}$ & $f$ & $\begin{array}{l}\Delta \mathrm{da}= \\
\Delta \mathrm{d} \mathbf{b}\end{array}$ & $\Delta \mathrm{d} \boldsymbol{\varphi}$ & $\Delta \mathrm{d} c$ & $\Delta \mathrm{dg}$ & $\Delta \mathrm{d} \boldsymbol{\varepsilon}$ & & & & & c & & & g & & & $\varepsilon$ & \\
\hline & \multirow[t]{2}{*}{$(\mathrm{mm})$} & \multirow[t]{2}{*}{$(\mathrm{mm})$} & \multirow[t]{2}{*}{$(\mathrm{mm})$} & \multirow[t]{2}{*}{$(\mathrm{mm})$} & \multirow[t]{2}{*}{$(\mu \mathrm{m})$} & \multirow{2}{*}{$\begin{array}{c}\text { (Degrees } \\
\cdot 10^{-3} \text { ) }\end{array}$} & \multirow[t]{2}{*}{$(\mu \mathrm{m})$} & \multirow[t]{2}{*}{$(\mu \mathrm{m})$} & \multirow[t]{2}{*}{ (\%) } & \multirow[t]{2}{*}{$(\mu \mathrm{m})$} & \multicolumn{2}{|c|}{$\begin{array}{l}\text { (Degrees } \\
\cdot 10^{-3} \text { ) }\end{array}$} & \multicolumn{3}{|c|}{$(\mu \mathrm{m})$} & \multicolumn{3}{|c|}{$(\mu \mathrm{m})$} & \multicolumn{3}{|c|}{ (\%) } \\
\hline & & & & & & & & & & & (i) $=$ (ii) & (iii) & $\mathrm{i}$ & ii & iii & $\mathrm{i}$ & ii & iii & $\mathrm{i}$ & ii & iii \\
\hline 1 & 184 & 19.5 & 70 & 38 & \pm 40 & \pm 65.5 & \pm 62 & \pm 106 & \pm 0.022 & 7.3 & 0.006 & 0.012 & 2 & 9 & 11 & 6 & 13 & 19 & 0.003 & 0.008 & 0.011 \\
\hline 2 & 239 & 14.5 & 43 & 38 & \pm 40 & \pm 106.6 & \pm 67 & \pm 138 & \pm 0.017 & 7.3 & 0.01 & 0.02 & 2 & 10 & 12 & 9 & 16 & 25 & 0.004 & 0.007 & 0.011 \\
\hline 3 & 238 & 14.5 & 58 & 28 & \pm 40 & \pm 79 & \pm 60 & \pm 99 & \pm 0.017 & 7.3 & 0.007 & 0.014 & 2 & 9 & 11 & 6 & 13 & 18 & 0.002 & 0.006 & 0.008 \\
\hline 4 & 238 & 20.8 & 70.9 & 23 & \pm 40 & \pm 64 & \pm 63 & \pm 89 & \pm 0.017 & 7.3 & 0.006 & 0.012 & 2 & 9 & 12 & 4 & 12 & 16 & 0.003 & 0.009 & 0.012 \\
\hline 5 & 184 & 19.5 & 70 & 20 & \pm 9 & \pm 14.7 & \pm 14 & \pm 19 & \pm 0.005 & 7.3 & 0.006 & 0.012 & 2 & 9 & 11 & 4 & 12 & 16 & 0.002 & 0.007 & 0.009 \\
\hline
\end{tabular}

